\title{
A DISCRIMINAÇÃO NO DISCURSO SOBRE O REFÚGIO NO BRASIL: UM ESTUDO SOBRE O EMPREGO PRONOMINAL E DISCLAIMERS
}

\begin{abstract}
Mariana Kuhlmann ${ }^{\mathrm{i}}$
Resumo: Segundo relatório publicado pelo Instituto Adus de Reintegração do Refugiado (2016), há, na sociedade brasileira, uma atitude de tolerância e resistência em relação àqueles que solicitam refúgio no Brasil por não se enquadrarem no padrão de migrante ideal (SEYFERTH, 2002). Desse modo, é possível afirmar que há uma discriminação velada por discursos vinculados a um imaginário de receptividade (KARNALL, 2016 apud OLIVEIRA JÚNIOR 2016). O presente artigo propõe uma discussão sobre as atitudes de discriminação no contexto do refúgio. Para dar encaminhamento à discussão, será analisado o emprego dos pronomes nós e eles em discursos sobre a presença do sujeito refugiado na sociedade à luz do arcabouço teórico elencado por Van Dijk (2000), especificamente ao que se refere aos disclaimers. A análise proposta será orientada com vistas a verificar como esses pronomes revelam atitudes de mera tolerância e aparente aceitação, evidenciando a configuração de uma discriminação velada.
\end{abstract}

Palavras-chave: Disclaimers. Refúgio. Discriminação. Tolerância.

Abstract: According to the report published by the Institute Adus of Reintegration of Refugees (2016), there is, in Brazilian society, an attitude of tolerance and resistance in relation to those requesting refuge in the country that do not fit the ideal migrant pattern (SEYFERTH, 2002). Thus, there are veiled discrimination discourses related to an imaginary of receptivity (KARNAL, 2016 apud OLIVEIRA, JÚNIOR 2016). This article proposes a discussion on discrimination attitudes in the context of refuge. As a pole of analysis figures the use of pronouns us and them in discourses on the subject of the refugee presence in Brazilian society. The data analysis will be guided by the theoretical framework proposed by Van Dijk (2000) concerning the discursive strategy called disclaimers, in order to verify how these pronouns reveal attitudes of mere tolerance and apparent acceptance and to discuss how these attitudes shape veiled discrimination.

Keywords: Disclaimers. Refuge. Discrimination. Tolerance.

\footnotetext{
'Mestranda pelo Programa de Pós-Graduação em Filologia e Língua Portuguesa da Universidade de São Paulo (USP). E-mail: mariana_kuhlmann23@hotmail.com.
} 
EID\&A - Revista Eletrônica de Estudos Integrados em Discurso e Argumentação, Ilhéus, n. 12, jul/dez.2016.

\section{Introdução}

Segundo dados fornecidos pelo Comitê Nacional para os Refugiados (2015), há um total de 8.400 refugiados reconhecidos no Brasil. Desse total, $70,7 \%$ homens e $29,3 \%$ mulheres. Esses homens e mulheres compõem um grupo culturalmente heterôgeneo, sendo que a nacionalidade mais acolhida naquele ano foi a síria (2.077 refugiados), seguida pela angolana (1.480) e a colombiana (1.093).

O presente estudo se propõe a analisar em que medida esses homens e mulheres são efetivamente acolhidos pela sociedade brasileira. Para isso, problematizaremos a questão da discriminação por meio da hipótese de que persiste uma discriminação velada que é praticada contra aqueles que se encontram na condição de refugiados no Brasil e que pode ser apreendida no discurso, por mais que seja encoberta por estratégias discursivas. Nesses termos, parte-se do pressuposto de que há, no discurso sobre o refúgio, um nós, referente aos brasileiros nascidos e residentes no Brasil, que mantém um expressivo distanciamento de um eles, referente aos sujeitos que se encontram na condição de refugiados.

Iniciaremos a discussão com um breve panorama histórico do refúgio no mundo e no Brasil. Daremos prosseguimento à discussão ao analisarmos o padrão de migrante ideal e o imaginário associado ao Brasil como sendo um país pacífico e acolhedor. Depois nos ateremos a explanar o arcabouço teórico que fundamentará a análise de um corpus, formado por respostas extraídas do questionário utilizado na formulação do Relatório do Instituto Adus de Reintegração ao Refugiado (2016), vinculado ao Programa de Advocacy. Por fim, após completar a incursão teórica proposta, desenvolveremos a análise propriamente dita com vistas a identificar os marcadores de diferença que permeiam o discurso sobre o refúgio no Brasil e que revelam em que medida a discriminação contra o sujeito refugiado se configura.

Com base em Hall (2003), Van Dijk (2000) e Silva (2012), assumimos que os pronomes nós e eles, no âmbito do discurso, não são meras categorias gramaticais e revelam particularidades da conjuntura social que privilegiam uns e discriminam outros.

Hipotetizamos que, ao analisarmos a discriminação praticada contra refugiados no Brasil à luz do emprego dos pronomes nós e eles, será possível apreender em que medida há no discurso - de uma suposta sociedade de acolhimento - uma atitude de condescendência que aceita, com uma série 
EID\&A - Revista Eletrônica de Estudos Integrados em Discurso e Argumentação, Ilhéus, n. 12, jul/dez.2016.

ressalvas e desconfianças, e tolera, mas não dialoga e não incentiva a integração e inclusão desse grupo na sociedade.

Podemos sumarizar os objetivos propostos da seguinte forma:

- analisar o emprego dos pronomes nós e eles nos discursos da suposta sociedade de acolhimento;

- verificar em que medida esses pronomes revelam atitudes de mera tolerância e aceitação aparente;

- discutir de que modo essas atitudes configuram uma discriminação velada.

\section{Aspectos históricos do refúgio}

Historicamente, as origens do refúgio enquanto recurso institucional de proteção internacional remonta à década de 1920, devido à necessidade de acolher contingentes populacionais vitimados pela Primeira Guerra Mundial.

Em 1921, há a nomeação de um Alto Comissário para os Refugiados pela Liga das Nações. A partir desse momento, o Alto Comissário passou por algumas mudanças institucionais, mas suas funções referentes ao atendimento de refugiados permaneceram basicamente as mesmas, conforme Sprandel; Milesi (2003, p. 113) discutem:

A proteção formal aos refugiados por parte da comunidade internacional teve início em 1921, com a nomeação de um Alto Comissário para os Refugiados pela Liga das Nações. Mais tarde, em função da perseguição a judeus não-arianos e opositores ao regime vigente na Alemanha, foi elaborada a Convenção de Genebra de 1933.

Com a Segunda Guerra Mundial, houve a necessidade de tornar as ações em prol dos refugiados mais efetivas e abrangentes. Assim, em 1938, é criado o Comitê Intergovernamental para Refugiados. Com o final da guerra, toda a comunidade internacional se vê diante do saldo de milhões de pessoas desabrigadas e da falta de medidas mais assertivas e institucionalizadas com vistas a atendê-las. Por essa razão, é aprovada a Convenção de Genebra:

A Convenção de Genebra define como refugiado toda a pessoa que, devido a fundados temores de ser perseguida por motivo de raça, religião, nacionalidade, grupo social ou opinióes políticas, se encontra fora do país de sua nacionalidade e que não pode ou, em virtude desse temor, não quer valer-se da proteção desse país, ou que, se não tem nacionalidade e se encontra fora do país no qual tinha sua residência habitual em consequência de tais acontecimentos, não pode ou, devido a esse temor, não quer a ele voltar (SPRANDEL \& MILESI, 2003, p. 116). 
EID\&A - Revista Eletrônica de Estudos Integrados em Discurso e Argumentação, Ilhéus, n. 12, jul/dez.2016.

Alguns anos mais tarde, é regulamentada a Declaração de Cartagena (1984), que apresenta uma conceituação mais inclusiva da condição de refugiado, considerando refugiado como sendo a condição de todo indivíduo que tenha fugido de seu país de origem porque sua vida, segurança e liberdade tenham sido ameaçadas por violência generalizada, agressão estrangeira, conflitos internos, violação massiva dos direitos humanos ou outras circunstâncias que tenham perturbado gravemente a ordem pública (SPRANDEL \& MILESI, 2003).

\subsection{0 refúgio no Brasil}

A instalação oficial no Brasil do escritório da Agência da Organização das Nações Unidas para Refugiados, doravante ACNUR, ocorreu em 1970. Naquele momento, o país optou pela cláusula de reserva geográfica prevista na Convenção de Genebra. Assim, para que um sujeito tivesse a sua solicitação de refúgio atendida, era necessário que ele apresentasse atributos específicos:

O País optou pela cláusula da reserva geográfica pela qual se comprometia a reconhecer como refugiados somente as pessoas que reunissem os requisitos próprios para configurar a condição de refugiadas em consequência de "acontecimentos ocorridos antes de $1^{\circ}$ de janeiro de 1951 na Europa". (SPRANDEL \& MILESI, 2003, p. 118).

Somente em 1989, a cláusula foi revogada como consequência da recepção e do reconhecimento de refugiados iranianos. A partir de então, foi recebido um número tão expressivo de refugiados que, em 1997, a população de indivíduos nessa condição atingiu a ordem de três mil pessoas. Por essa razão, fez-se necessária a elaboração de uma lei que incorporasse os princípios gerais das convenções e protocolos internacionais mais modernos da área. Em 22 de julho de 1997, foi aprovada a Lei 9.474 que representou um importante avanço conceitual no tratamento dispensado à população refugiada:

Preocupou-se o legislador brasileiro com a grave e generalizada violação dos direitos humanos e mostrou-se aberto, seguindo a tendência internacional na matéria, à possibilidade do acolhimento em solo nacional de grupos de refugiados e não apenas de casos individuais (VERWEY, ZERBINI \& SILVA, 2000, p. 184).

Atualmente, o Brasil é considerado pela comunidade internacional como sendo um país receptivo a grupos refugiados de diferentes nacionalidades e 
EID\&A - Revista Eletrônica de Estudos Integrados em Discurso e Argumentação, Ilhéus, n. 12, jul/dez.2016.

pioneiro nas Américas no que concerne ao acolhimento e à integração (MOREIRA, 2005).

No entanto, é preciso reconhecer que tal pioneirismo não coaduna com o que é experenciado pelo sujeito que se encontra na condição de refugiado na sociedade brasileira. Segundo Jubilut (2015), a discriminação é apontada por migrantes e refugiados como uma das maiores dificuldades enfrentadas ao acesso a serviços básicos e à integração.

Em consonância com essa afirmação, há o posicionamento de Moreira; Baeninger (2010), que afirma que a sociedade brasileira ainda oferece resistência ao acolhimento de grupos refugiados, sendo os obstáculos mais críticos a falta de moradia, a dificuldade de encontrar emprego e atendimento médico e a discriminação. Segundo as autoras: "A sociedade brasileira não sabe ao certo o que é um refugiado e com frequência os reconhece como fugitivos da justiça, tornando a integração na sociedade e no mercado de trabalho ainda mais difícil" (MOREIRA; BAENINGER, 2010, p. 31)

Assim, por mais que haja um significativo reconhecimento da comunidade internacional do Brasil como país de acolhimento e de recepção de contingentes populacionais que solicitam refúgio, o sujeito que se encontra nessa condição ainda sofre discriminação e enfrenta sérias dificuldades para se integrar à sociedade.

\section{A discriminação sob as máscaras do discurso}

A discriminação no contexto do refúgio e a conjuntura apontada no tópico anterior tornam pertinente a discussão de duas questões: (1) a imagem, histórica e discursivamente construída, do migrante ideal e (2) a imagem acolhedora e receptiva, também histórica e discursivamente construída, da sociedade brasileira.

\subsection{0 migrante ideal}

De acordo com Seyferth (2002), há uma categorização que rotula a população de migrantes, sejam eles refugiados ou não, havendo aqueles que são desejados e aqueles que são indesejados. Esses rótulos que circulam, segundo a autora, remontam ao período colonial e colocam o migrante ideal, ou seja, o desejado, como "um branco adjetivado, sendo excluídos os doentes, portadores de deficiência física e mental, velhos, criminosos, gente 
EID\&A - Revista Eletrônica de Estudos Integrados em Discurso e Argumentação, Ilhéus, n. 12, jul/dez.2016.

de conduta nociva, refugiados, apátridas e as etnias inassimiláveis" (SEYFERTH, 2002, p. 143). Aqueles que migram sob quaisquer condições e não apresentam um perfil que se conforme nesse padrão de migrante ideal são considerados um fardo e tendem a ficar sujeitos a práticas discriminatórias.

É também de suma importância reconhecer o caráter heterogêneo dos contingentes migratórios que se dirigem ao Brasil no contexto do refúgio e que se contrapõe às expectativas atreladas ao imaginário de migrante ideal: "Desde o final do século XIX, criou-se a ideia de que o migrante para ser aceito teria de ser branco e europeu, e os imigrantes atuais são indígenas que falam espanhol, como os bolivianos, ou negros que falam francês ou crioulo, como os haitianos" (FIORAVANTI, 2015, p. 18).

\subsection{Um povo acolhedor e pacífico}

Recentemente, estudos desenvolvidos pela Anistia Internacional (2016) constataram que a sociedade brasileira admite a presença de refugiados, mas assume uma posição de distanciamento, uma vez que os considera como elementos estranhos que vieram usufruir de benefícios supostamente exclusivos daqueles que nasceram e residem no Brasil ou ainda que sustenta a ideia de que eles vieram sobrecarregar os serviços oferecidos pela já parca infraestrutura brasileira.

Nessa conjuntura, aqueles que se encontram na condição de refugiados são tolerados por meio uma atitude que se restringe à aceitação, mas não é efetivamente acolhedora ou propícia ao diálogo. Para Lopes (2012), essa proposta de tolerância que oferece forte resistência ao diálogo apresenta graves consequências como a marginalização de grupos minoritários mascarada por uma aparente receptividade que, na prática, não promove a integração e, ainda, coloca a diversidade cultural como um problema.

Conforme consta em Rodrigues (2016 apud OLIVEIRA JÚNIOR, 2016, p. 45), durante o período imperial, houve um forte investimento na propagação de narrativas que sustentam o imaginário de um Brasil acolhedor e pacífico: "Embora desgastadas pelo tempo, as narrativas sobre um Brasil manso e acolhedor com as diferenças sobrevivem e são invocadas para maquiar a secular dificuldade em conviver com o diverso. Nosso falso pacifismo foi usado como elemento de unificação nacional". 
EID\&A - Revista Eletrônica de Estudos Integrados em Discurso e Argumentação, Ilhéus, n. 12, jul/dez.2016.

Discutir a configuração de tais narrativas ou até mesmo o histórico de todo esse imaginário não constitui os propósitos do presente estudo. No entanto, quando se discute a questão da discriminação em um contexto como o do refúgio, em que há a aceitação rasa do outro, permeada por uma série de ressalvas, é preciso considerar todo esse imaginário. Desse modo, identifica-se o seguinte contrassenso: a sociedade se afirma como acolhedora, mas paralelamente, persiste a secular dificuldade que temos de conviver com o diverso, com aquele que não se enquadra nos padrões.

Outros estudiosos amparam essa constatação: Karnal (2016 apud OLIVEIRA, JÚNIOR, 2016, p. 42) sugere que, como consequência dessas "narrativas de um Brasil manso e acolhedor", se fundamentou uma discriminação discursivamente velada: se, por um lado, há uma imagem de um povo que aceita e acolhe a todos, por outro, é possível constatar que tal aceitação e acolhimento é efetivamente dirigida a poucos. Oliveira Júnior (2016) ainda afirma, do mesmo modo e nos entremeios dessa discussão, que há uma aversão muito grande, na sociedade brasileira, de assumir conflitos e, por essa razão, se perpetua o mito de que o país é pacífico e tolerante.

Em síntese, podemos, a partir de diferentes perspectivas, assumir que, na sociedade, há, de fato, discriminação, mas tal discriminação não é explicitamente reconhecida ou assumida.

\section{Refúgio, discurso e discriminação}

Se há, então, uma discriminação velada, sugerida pelos estudiosos discutidos, cabe indagar como ela se configura no discurso. Neste tópico, iremos discorrer sobre como a análise do discurso tem sido e pode ser empregada na abordagem de contextos migratórios críticos, especificamente o refúgio. Em princípio, cabe elencar as considerações tecidas por Freitas (2008, p. 21):

Questões sobre migração têm sido tradicionalmente focadas a partir de áreas como a sociologia, a geografia, a antropologia entre outras. Uma proposta de análise do fenômeno sob a lupa da Linguística pode parecer desconexa mesmo para alguns estudiosos da área, acostumados com uma perspectiva analítica que dá primazia para descrições formais de propriedades da língua como sistema, conforme tem sido a ênfase da disciplina desde o seu florescer como ciência moderna. 
EID\&A - Revista Eletrônica de Estudos Integrados em Discurso e Argumentação, Ilhéus, n. 12, jul/dez.2016.

Aparentemente, propor um estudo linguístico sobre fenômenos migratórios pode parecer infundado. No entanto, quando reconhecemos que a experiência do refúgio coloca o sujeito em uma situação de incerteza e crise identitária (HALL, 2003), que tensiona aquilo que consideramos como sendo nosso contra aquilo que consideramos como sendo deles, o vínculo sobre fenômenos migratórios e língua começa a se revelar.

Silva (2012, p. 70) explana tais questões da seguinte forma:

Dizer, por sua vez, que a identidade e a diferença são resultado de atos de criação linguística significa dizer que elas são criadas por meio de atos de linguagem. Isto parece uma obviedade. Mas como tendemos a tomá-las como dadas, como "fatos da vida", com frequência esquecemos que a identidade e a diferença têm que ser nomeadas. É apenas por meio de atos de fala que instituímos a identidade e a diferença como tais. A identidade brasileira, por exemplo, é o resultado da criação de variados e complexos atos linguísticos que a definem como sendo diferente de outras identidades nacionais.

De acordo com o autor, é no discurso que é exercido o poder de definir aqueles que são nós e aqueles que são eles. Essa demarcação de fronteiras, essa separação, essa distinção que se constrói na língua por meio do discurso faz com que nós e eles não sejam apenas simples distinções gramaticais, mas sim, indicadores de posições-de-sujeito fortemente marcadas por relações de poder instauradas em contextos de migração.

\subsection{Sobre nós e eles}

A tensão que se instaura em contextos migratórios críticos e que tornam o sujeito vulnerável e marginalizado já foi abordada por Van Dijk (2000). Em seu estudo, o autor se concentrou em analisar diferentes categorias discursivas presentes em debates parlamentares sobre a imigração no contexto europeu, buscando abordar questões étnicas em geral.

Tanto as estruturas semânticas quanto as formais são discutidas de modo a descortinar a discriminação praticada contra imigrantes e refugiados. Especificamente, serão elencadas as considerações tecidas em relação aos pronomes nós e eles.

Segundo Van Dijk (2000, p. 95), a oposição entre nós e eles é prototípica na polarização do que ele chama de endogrupos e exogrupos. No contexto dos debates parlamentares, o autor verificou que o estudo de tal polarização expressa pelo emprego pronominal é muito útil, uma vez que estabelece 
EID\&A - Revista Eletrônica de Estudos Integrados em Discurso e Argumentação, llhéus, n. 12, jul/dez.2016.

quem são aqueles referidos como o outro, o indesejado, o intruso, e aqueles que não são assim referidos':

Também na fronteira entre a sintaxe e a semântica, o estudo dos pronomes tem se mostrado relevante, especialmente no estudo do discurso político. De fato, a oposição entre nós e eles se tornou prototípica da polarização de (representações mentais sobre) endogrupos e exogrupos. Também em debates parlamentares, é muito útil estabelecer a quem exatamente está se referindo quando os falantes usam 'nós' e 'eles'.

A análise proposta por Van Dijk (2000; 2003) ressalta que a imigração é comumente definida, do ponto de vista da sociedade de destino, como um problema, um fardo financeiro e até mesmo uma ameaça ao nosso bem-estar social e à nossa cultura. Nesses termos, os refugiados tendem a ser categorizados como eles, aqueles que abusam dos serviços públicos. Além disso, outra concepção recorrente é a de que, por falta de uma suposta infraestrutura organizada, nós não temos condições de recebê-los, apesar de reconhecermos a lamentável situação em que eles se encontram.

Em geral, tais posições tendem a ser discursivamente articuladas por meio de movimentos semânticos que, muitas vezes, mascaram uma atitude de rejeição e discriminação assumida por nós em relação a eles. Esses movimentos semânticos são estratégias denominadas disclaimers pelo autor.

Para o autor, a função dos disclaimers consiste em enunciar uma atitude de desaprovação ou repúdio em relação a um grupo sem expor negativamente a face de quem enuncia tal atitude (VAN DIJK, 2003, p. 50). Isso porque os falantes tendem a assegurar que os ouvintes fiquem com uma impressão positiva da imagem que é apresentada por eles. Logo, se há um teor de preconceito na fala, esse teor é mascarado por essas estratégias.

Ao todo, Van Dijk (2000, p. 92, itálicos nossos) categoriza as seguintes estratégias: negação aparente, concessão aparente, empatia aparente, ignorância aparente, desculpa aparente, reversão e transferência²:

\footnotetext{
${ }^{1}$ No original: "Also at the border of syntax and semantics, the study of pronouns has often been shown to be relevant, especially also in the study of political discourse. Indeed, the opposition between Us and Them, has become prototypical of the polarization of (mental representations about) in-groups and out-groups. Also in parliamentary debates, thus, it is very useful to establish who exactly are being referred to when speakers use 'We' and 'They"'.

${ }^{2}$ No original: "Quite typical in discourse about immigrants and minorities is the use of special semantic moves that implement the possible contradiction between positive self-presentation and negative other-presentation, as is the case for well-known disclaimers such as the Apparent Denial ("I have nothing against X, but..."). These are essential moves in the management of the impression the recipients may have about the speaker. Other disclaimers are: Apparent Concession ("They are not criminal, but..."), Apparent Empathy ("They have had lots of difficulties in their own
} 
EID\&A - Revista Eletrônica de Estudos Integrados em Discurso e Argumentação, llhéus, n. 12, jul/dez.2016.

Bem típico do discurso sobre imigrantes e minorias é o uso de movimentos semânticos especiais que implementam uma possível contradição entre a apresentação positiva do self e a apresentação negativa do outro, como é o caso dos famosos disclaimers, como a Negação Aparente ("Eu não tenho nada contra $\mathrm{X}$, mas..."). Trata-se de movimentos essenciais para o gerenciamento da impressão que os receptores possam ter sobre o falante. Outros disclaimers são: Concessão Aparente ("Eles não são criminosos, mas..."), Empatia Aparente ("Eles passaram por muitas dificuldades em seu próprio país, mas..."), Ignorância Aparente ("Eu não sei, mas..."), Desculpa Aparente ("Me perdoe, mas..."), Reversão (culpar a vítima) e Transferência ("Não tenho problema algum com $X$, mas meus clientes..."), entre outros.

\section{0 corpus e metodologia}

O corpus que será analisado nessa ocasião será composto por entrevistas obtidas pelo Programa de Advocacy do Instituto Adus de Reintegração do Refugiado no biênio de 2015-2016.

A pesquisa foi desenvolvida por meio de um questionário ${ }^{3}$, compartilhado em redes sociais e respondido virtualmente 4 . Ao todo, 226 pessoas participaram da pesquisa. O perfil dos participantes foi restrito a brasileiros que residem no país, que possuem ensino médio completo e acesso à internet e que estão inseridos na faixa etária dos 18 aos 40 anos. Ao todo, o questionário foi composto por quatro perguntas, mas, para essa ocasião, no debruçaremos sobre apenas duas delas, a saber:

1. Você acha que os refugiados podem colaborar com a sociedade brasileira?

1.1 Caso tenha respondido "sim" ou "não" na questão anterior, poderia nos dar mais detalhes?

Para desenvolver a proposta de estudo de modo condizente com a extensão do presente artigo, serão compiladas 10 respostas afirmativas (vf. Quadro 1) extraídas do corpus de modo a tornar possível a realização de uma análise qualitativa dos dados coletados. Como o polo linguístico selecionado

country, but..."), Apparent Ignorance ("I don't know, but..."), Apparent Excuse ("I am sorry, but..."), Reversal (Blaming the victim) and Transfer ("I have no problem with X, but my clients...") and others".

${ }^{3}$ Disponível:<https://docs.google.com/forms/d/16MI4tMiXmPfZN5P4zEzapySgb3sW_HDeTFYZYMnl cnc/viewform>. Acesso em: 14 fev. 2016.

${ }^{4}$ Para responder ao questionário, não era necessário que o entrevistado estivesse logado em uma conta específica de e-mail. Além disso, ele foi compartilhado em diferentes páginas e foi aberto ao público. A pesquisa foi direcionada a pessoas maiores de idade que completaram o ensino médio. Não houve distinção de gênero. 
EID\&A - Revista Eletrônica de Estudos Integrados em Discurso e Argumentação, llhéus, n. 12, jul/dez.2016.

consiste no emprego dos pronomes eles/nós, fundamentaremos a presente análise nas considerações tecidas por Van Dijk (2000) com o intuito de verificar que traços, positivos ou negativos, são atribuídos a cada um dos dois grupos e quais movimentos semânticos são identificados em cada um dos contextos de uso.

\section{Análise de dados}

Antes de procedermos à análise de dados, é importante reforçar que, quando analisamos um enunciado que foi dito por um sujeito em determinado contexto, não estamos apenas analisando aquilo que o sujeito afirmou sobre um determinado assunto. Isso porque, conforme explanado por Rossi-Landi (1985), as palavras e as mensagens não são individuais; elas são uma operação coletiva, um trabalho humano feito a várias mãos, ou melhor, a várias vozes. Por isso, consideramos que, ao analisarmos o corpus apresentado, não estamos só acessando as opiniões particulares de cada um dos entrevistados, mas, sobretudo, a atitude assumida pela sociedade, por aqueles que estão inclusos na categoria nós em relação àqueles que se encontram sob a condição de refugiados, inclusos na categoria eles.

Os dados a serem analisados foram compilados ${ }^{5}$, numerados e reunidos no Quadro 1.

\footnotetext{
${ }^{5}$ Os dados apresentados foram compilados conforme constavam no corpus original e não sofreram nenhum tipo de correção ortográfica ou gramatical.
} 
EID\&A - Revista Eletrônica de Estudos Integrados em Discurso e Argumentação, Ilhéus, n. 12, jul/dez.2016.

\section{Quadro 1. Compilação de respostas oferecidas às questões 1 e 1.1}

\begin{tabular}{|c|c|}
\hline $\begin{array}{l}\text { Você acha que os } \\
\text { refugiados podem } \\
\text { colaborar } \\
\text { positivamente com } \\
\text { a sociedade } \\
\text { brasileira? }\end{array}$ & $\begin{array}{l}\text { Caso tenha respondido "sim" ou "não" na questão anterior, } \\
\text { poderia nos dar mais detalhes? }\end{array}$ \\
\hline 1) $\mathrm{Sim}$ & $\begin{array}{l}\text { Acredito que nós temos muito aprender com eles, mas é } \\
\text { preciso reconhecer também que estamos em crise e que não é } \\
\text { fácil recebê-los. }\end{array}$ \\
\hline 2) $\mathrm{Sim}$ & $\begin{array}{l}\text { Sim, nós sabemos que eles podem colaborar com a sociedade } \\
\text { com a sua mão de obra, apesar de serem refugiados. }\end{array}$ \\
\hline 3) $\mathrm{Sim}$ & $\begin{array}{l}\text { Eu não tenho nada contra eles, por isso acho que são bem } \\
\text { vindos e podem contribuir. Mas gostaria de deixar claro que } \\
\text { eles tem que trabalhar para pagar a ajuda que estão } \\
\text { recebendo porque os serviços públicos do Brasil não ajudam } \\
\text { nem os brasileiros direito. }\end{array}$ \\
\hline 4) $\operatorname{Sim}$ & $\begin{array}{l}\text { Poderiam contribuir para com a economia desde que aceitem } \\
\text { nossa cultura e nossas leis. Também aceitem trabalhar e pagar } \\
\text { nossos impostos como todos fazemos, basicamente. Caso } \\
\text { contrário não são honráveis para tal. }\end{array}$ \\
\hline 5) $\mathrm{Sim}$ & $\begin{array}{l}\text { Claro, eles são bem vindos. São pessoas que podem ter } \\
\text { conhecimento e formação, além de mão de obra para o país. } \\
\text { Podem ocupar diversos cargos, desde que estejam preparados } \\
\text { para tal atividade, trazendo conhecimento de outros lugares. }\end{array}$ \\
\hline 6) $\operatorname{Sim}$ & $\begin{array}{l}\text { Eles podem contribuir com a gente sem sombra de dúvidas. } \\
\text { Cidadãos problemáticos existem em qualquer cultura. }\end{array}$ \\
\hline 7) $\mathrm{Sim}$ & $\begin{array}{l}\text { Ele são pessoas que enfrentam situações muito difíceis e } \\
\text { podem de fato colaborar, mas trazem muitos problemas } \\
\text { também. }\end{array}$ \\
\hline 8) $\mathrm{Sim}$ & $\begin{array}{l}\text { Eu não sou contra a presença dos refugiados e eles até podem } \\
\text { contribuir sim. Mas a gente até pode aceitar, ma a gente sabe } \\
\text { que o Brasil já tem os nossos problemas, não é mesmo? }\end{array}$ \\
\hline 9) $\mathrm{Sim}$ & $\begin{array}{l}\text { Gostaria de complementar a resposta anterior dizendo que, } \\
\text { sim, eles podem colaborar. Por outro lado, nós sabemos que o } \\
\text { próprio governo não ajuda nem os brasileiros. Então não sei } \\
\text { como eles podem colaborar, mas sei que eles podem e, apesar } \\
\text { de tudo, são bem-vindos. }\end{array}$ \\
\hline 10) $\mathrm{Sim}$ & $\begin{array}{l}\text { O próprio Brasil foi formado por pessoas de outros países, por } \\
\text { isso acredito que eles até podem colaborar. Mas as diferenças } \\
\text { culturais e linguísticas são um problema sério e eles precisam } \\
\text { se esforçar para serem como nós. }\end{array}$ \\
\hline
\end{tabular}


EID\&A - Revista Eletrônica de Estudos Integrados em Discurso e Argumentação, Ilhéus, n. 12, jul/dez.2016.

Na resposta (1), o entrevistado afirma ser favorável à presença deles (os refugiados) e reconhece, em princípio, tal presença como sendo positiva e fundamentada em trocas culturais. No entanto, nota-se que essa posição do entrevistado é permeada por uma atitude de concessão e empatia aparentes, uma vez que nós estamos em crise e não é fácil "recebê-los". Posição semelhante é observada na resposta (5), pois o entrevistado reconhece eventuais benefícios que podem ser trazidos pelos refugiados, desde que eles estejam realmente preparados.

Por sua vez, na resposta (2), o entrevistado afirma que eles podem colaborar, apesar de serem refugiados, numa atitude de concessão aparente que coloca o sujeito refugiado como um problema e que, apesar de ser um problema, é aceito por nós.

A negação aparente é visível na resposta (3): o entrevistado declara não ter nada contra eles e que eles são bem-vindos. Em contrapartida, eles, por não serem brasileiros, devem contribuir financeiramente e pagar pela ajuda que estão recebendo. Desse modo, o entrevistado coloca os refugiados com não pertencentes ao grupo dos brasileiros. Na resposta (4), também observamos uma posição que aceita os refugiados, mas sob a condição de que eles se submetam a nossa cultura e às nossas leis. Consideramos que a atitude de concessão aparente se faz presente nessa resposta também, uma vez que eles precisam agir e contribuir financeiramente como nós, apesar de não serem como nós.

Já na resposta (6), o entrevistado também apresenta uma atitude de concessão e empatias aparentes. A chegada deles é considerada como "bemvinda", mas, por outro lado, eles são vistos por nós como "cidadãos problemáticos", que existem em quaisquer lugares.

Ao reconhecer a vulnerabilidade social e as circunstâncias críticas enfrentadas por eles em seus países de origem, o autor da resposta (7) apresenta uma posição de empatia e concessão aparentes, já que tal reconhecimento é contrariado pela constatação de que há uma série de problemas que são trazidos junto com os refugiados.

O entrevistado que forneceu a resposta (8) se coloca numa posição de negação aparente. Isso porque ele nega possuir preconceitos contra os refugiados e concorda que eles podem "até" colaborar positivamente com a sociedade. No entanto, ele também afirma que o Brasil "já tem os nossos 
EID\&A - Revista Eletrônica de Estudos Integrados em Discurso e Argumentação, Ilhéus, n. 12, jul/dez.2016.

problemas", sugerindo que a recepção de refugiados seria mais um problema a se somar com os outros já vigentes.

Do mesmo modo, a resposta (9) assume uma posição semelhante. $O$ entrevistado se coloca como favorável e afirma que o refugiado pode colaborar positivamente, mas, por outro lado, ele reconhece que o país já enfrenta os nossos problemas. Assim, ele conclui que não sabe como (ignorância aparente) eles podem colaborar, mas, ao mesmo tempo, alega que eles podem colaborar (concessão aparente).

Por fim, na resposta (10), o entrevistado afirma que o próprio Brasil foi formado por pessoas de outros países e, por essa razão, eles são bem-vindos e podem colaborar, numa atitude de empatia e concessão aparentes. Tal atitude se torna evidente quando o autor coloca como condição a necessidade de que eles se "esforcem" para serem como nós.

Com base nas estratégias de rejeição analisadas nas respostas, constatamos que é recorrente a categorização que coloca aqueles que são brasileiros, nascidos e residentes no Brasil, sob o pronome nós - integrantes do endogrupo - e que coloca aqueles que se encontram na condição de refugiados sob o pronome eles - integrantes do exogrupo. Essa polarização se fundamenta de tal forma que coloca a categoria nós numa posição de domínio em relação a eles ensejando, assim, uma relação de poder que marginaliza uns e privilegia outros.

Por fim, cabe ainda destacar que os entrevistados se empenharam em assumir uma posição de receptividade perante a questão postulada. Mas, subjacente a essa posição, notou-se um esforço constante em ressalvar a presença do sujeito que se encontra na condição de refugiado, uma vez que, de acordo com o que foi alegado no corpus, cabe a ele contribuir economicamente com o país que o recebeu, submeter-se às condições impostas pela sociedade e, ainda, demonstrar como a sua presença pode ser vantajosa. Logo, concluímos que a posição de receptividade assumida por uns precisa ser ponderada e problematizada.

\section{Considerações finais}

Os dados apresentados e discutidos indicaram que há, de fato, um discurso que aceita, mas coloca uma distinção clara entre nós e eles. Também foi possível verificar que essa distinção se fundamenta em atitudes de 
EID\&A - Revista Eletrônica de Estudos Integrados em Discurso e Argumentação, Ilhéus, n. 12, jul/dez.2016.

concessão, empatia, ignorância e negação aparentes, sendo as duas primeiras mais recorrentes.

Ao cotejarmos tal constatação com a hipótese de que há uma discriminação velada, que aceita o outro, porém com ressalvas e distanciamento, observamos que ambas são complementares. No corpus analisado, os entrevistados alegaram inicialmente que os refugiados podem colaborar positivamente, que eles são bem-vindos, que a presença deles pode trazer contribuições relevantes. Mas, em contrapartida, essas alegações são contrariadas pela constatação de que eles são mais um problema para o país. Também é frequente a menção de condições que submetem eles ao nosso modo de ser, à obrigação de que eles devem ser produtivos e compensar eventuais desequilíbrios provocados em nossa infraestrutura.

Essas estratégias discursivas não apenas revelam a face do discurso que discrimina e nos levam a constatar em que medida esse discurso é velado por condições e questões de ordem sociocultural. Sobretudo, tais estratégias também evidenciam como a condição do sujeito submetido à experiência do refúgio no Brasil é marginalizada. Os movimentos semânticos articulados no discurso nos dão mobilidade para proteger a nossa face e encurralar o outro em uma categoria que o aprisiona sob o rótulo de eles.

Por essas razões, as respostas, analisadas à luz de Van Dijk (2000), corroboram com a afirmação de que há uma discriminação velada praticada contra os refugiados, seja ela pautada numa dificuldade sociocultural de reconhecermos os nossos próprios preconceitos, seja ela pautada numa suposta imagem de acolhimento e receptividade, seja ela pautada nos padrões de migrante ideal que perduram desde o findar do século XIX.

Concluímos, portanto, com a constatação de que é necessário propor medidas governamentais e estudos que questionem efetivamente as raízes da tolerância em nossa sociedade em diferentes contextos, de modo a revisitar discursos cotidianos e recorrentes e abalar relações de poder que marginalizam uns e privilegiam outros. 
EID\&A - Revista Eletrônica de Estudos Integrados em Discurso e Argumentação, llhéus, n. 12, jul/dez.2016.

\section{Referências}

ADUS. Relatório Anual Adus. São Paulo: Instituto Adus de Reintegração do Refugiado, 2016.

ANISTIA INTERNACIONAL. Refugees Welcome Index. Disponível em: < https://www.amnesty.org/en/latest/news/2016/05/refugees-welcome-index-showsgovernment-refugee-policies-out-of-touch/>. Acesso em: 05 jun. 2016.

CONARE. Refúgio no Brasil. Disponível em: <http://pt.slideshare.net/justicagovbr/refgio-no-brasil-51820929>. Acesso em: 10 jan. 2016.

FIORAVANTI, Carlos. As raízes da resistência. Revista Fapesp, São Paulo: Fundação de Amparo à Pesquisa, n. 236, p. 16-23, 2015.

FREITAS, Lúcia Gonçalves. Discurso e identidade em narrativas de migrantes. Tese de Doutorado. Brasília: Universidade de Brasília, 2008.

HALL, Stuart. A identidade cultural na pós-modernidade. Trad. Tomaz Tadeu da Silva e Guacira Lopes Louro. Rio de Janeiro: DP\&A, 2003.

JUBILUT, Liliana Lyra. (Org.). Migrantes, apátridas e refugiados. Brasília: IPEA e Ministério da Justiça, 2015. Disponível em: < http://pensando.mj.gov.br/publicacoes/?pub_id=1003906>. Acesso em: 10 fev. 2016.

LOPES, Ana Maria D'Ávila. Da coexistência a convivência com o outro: entre o multiculturalismo e a interculturalidade. Revista Interdisciplinar de Mobilidade Humana. Brasília: CSEM, v. 20, n. 38, p. 67-81, 2012.

MOREIRA, Julia Bertino; BAENINGER, Rosana. A integração local de refugiados no Brasil. Forced Migration Review. Oxford: University of Oxford, v. 35, p. 30-31, 2010.

OLIVEIRA JÚNIOR, Almir. Mitos fundadores. Revista Página 22, n.100 São Paulo: FGV, p.42-49, 2016.

ROSSI-LANDI, Ferruccio. A linguagem como trabalho e como mercado. Trad. Aurora Fornoni Bernardini. São Paulo: Difel, 1985.

SEYFERTH, Giralda. Colonização, imigração e a questão racial no Brasil. Revista USP. São Paulo: Universidade de São Paulo, n. 53, p. 117-149, 2002.

SILVA, Tomaz Tadeu da. Identidade e diferença: a perspectiva dos estudos culturais. Rio de Janeiro: Vozes, 2012. 
EID\&A - Revista Eletrônica de Estudos Integrados em Discurso e Argumentação, Ilhéus, n. 12, jul/dez.2016.

SPRANDEL, Márcia Anita; MILESI, Rosita. O acolhimento a refugiados no Brasil: histórico, dados e reflexões. In: MILESI, Rosita (Org.). Refugiados: realidade e perspectivas. Brasília: CSEM/IMDH, p.113-134, 2003.

VAN DIJK, Teun. On the analysis of parliamentary debates on immigration. In: WODAK, Ruth (Org.). The semiotics of racism. Approaches to critical discourse analysis. Viena: Passagen Verlag, p. 85-103, 2000.

VAN DIJK, Teun. Ideología y discurso - Una introducción multidisciplinaria. Barcelona: Ariel, 2003.

VERWEY, Anton; ZERBINI, Renato.; SILVA, Ariel. A percepção brasileira dos refugiados. Revista Brasileira de Política Internacional. Brasília: Instituto Brasileiro de Relações Internacionais, v. 43, n. 1, p. 183-185, 2000.

Forma de citação sugerida:

KUHLMANN, Mariana. A discriminação no discurso sobre o refúgio no Brasil: um estudo sobre o emprego pronominal e disclaimers. EID\&A - Revista Eletrônica de Estudos Integrados em Discurso e Argumentação, Ilhéus, n. 12, p. 174-190, jul/dez.2016.

Recebido em: 12/10/2016

Aprovado em: 20/11/2016 